\title{
Molecular epidemiology of avian influenza viruses circulating among healthy poultry bred in farms in northern Vietnam
}

Hiroki Takakuwa $^{\text {a, b }}$, Tetsu Yamashiro ${ }^{\text {c, d* }}$, Mai Q. Le ${ }^{\text {e }}$, Lien S. Phuong ${ }^{\mathrm{f}}$, Hiroichi Ozaki ${ }^{\mathrm{g}, \mathrm{h}}$,

Ryota Tsunekuni $^{b}$, Tatsufumi Usui ${ }^{g}$, Hiroshi Ito ${ }^{\text {g, }}{ }^{\text {, }}$, Masami Morimatsu ${ }^{j}$, Yukiko Tomioka ${ }^{j}$, Tsuyoshi Yamaguchi $^{\mathrm{g}}$, Toshihiro Ito ${ }^{\mathrm{g}, \mathrm{i}}$, Toshiyuki Murase ${ }^{\mathrm{g}, \mathrm{h}}$, Etsuro Ono ${ }^{\mathrm{g}, \mathrm{k}^{*}}$, and Koichi Otsuki ${ }^{\mathrm{a}, \mathrm{b}, \mathrm{g}}$

${ }^{\text {a }}$ Faculty of Life Sciences, Kyoto Sangyo University, Kamigamo-motoyama, Kita, Kyoto 603-8555, Japan

${ }^{\mathrm{b}}$ Avian Influenza Research Centre, Kyoto Sangyo University, Kamigamo-motoyama, Kita, Kyoto 603-8555, Japan

${ }^{\mathrm{c}}$ Center for Infectious Disease Research in Asia and Africa, Institute of Tropical Medicine, Nagasaki University, 1-12-4 Sakamoto, Nagasaki 852-8523, Japan

${ }^{\mathrm{d}}$ Vietnam Research Station, Nagasaki University, 1 Yersin, Hanoi, Vietnam

${ }^{\mathrm{e}}$ Department of Virology, National Institute of Hygiene and Epidemiology, 1 Yersin, Hanoi, Vietnam

${ }^{\mathrm{f}}$ Vietnam Veterinary Association, 86 Truong Chinh, Hanoi, Vietnam

${ }^{\mathrm{g}}$ The Avian Zoonosis Research Center, Faculty of Agriculture, Tottori University, 4-101

Koyama, Tottori 680-8553, Japan

${ }^{\mathrm{h}}$ Department of Veterinary Microbiology, Faculty of Agriculture, Tottori University, 4-101

Koyama, Tottori 680-8553, Japan

${ }^{\mathrm{i}}$ Department of Veterinary Public Health, Faculty of Agriculture, Tottori University, 4-101

Koyama, Tottori 680-8553, Japan

${ }^{\mathrm{j}}$ Division of Disease Model Innovation, Institute for Genetic Medicine, Hokkaido University, Sapporo 060-0815, Japan

${ }^{\mathrm{k}}$ Laboratory of Biomedicine, Center of Biomedical Research, Graduate School of Medical Sciences, Kyushu University, Fukuoka 812-8582, Japan

*Corresponding Authors. 
Tel.: +81 92-642-6147; fax: +81 92-642-6165.

Email address: etsuro@anim.med.kyushu-u.ac.jp (E. Ono)

Tel.: +8195819 7876; fax: +81958197830.

Email address: tyamashi@nagasaki-u.ac.jp (T. Yamashiro) 


\section{ABSTRACT}

Repeated epizootics of highly pathogenic avian influenza (HPAI) virus subtype H5N1 among poultry were reported from 2003 to 2005 in Vietnam. More than 200 million poultry have been killed to control the spread of the disease. Human cases of H5N1 infection have been sporadically reported in an area where repeated H5N1 outbreaks among birds had occurred. A close contact with infected poultry was estimated as a route of transmission to cause human $\mathrm{H} 5 \mathrm{~N} 1$ infection, and the $\mathrm{H} 5 \mathrm{~N} 1$ viruses isolated from human cases were substantially identical to strains having circulated among poultry. The number of outbreaks caused by H5N1 subtype has decreased; however, subtype H5N1 strains have established their endemicity among poultry in Vietnam. In order to determine the prevalence of constellation of avian influenza virus including $\mathrm{H} 5 \mathrm{~N} 1$ circulating among poultry in northern Vietnam, surveillance was conducted during year 2006-2009. A subtype H5N1 strain was isolated from an apparently healthy duck reared in a farm in northern Vietnam in 2008 and was identified as an HPAI. In addition, a total of 26 avian influenza viruses with low pathogenicity were isolated from poultry and phylogenetic analysis on all of the eight gene segments revealed their diverse genetical backgrounds, implicating that reassortments have occurred frequently among strains in northern Vietnam. It is important to monitor the prevalence of influenza viruses among healthy poultry in an area where avian influenza viruses including subtype H5N1 are endemic.

Keywords: poultry / avian influenza virus / H5N1 / Vietnam 


\section{Introduction}

Since late 2003, highly pathogenic H5N1 influenza viruses have spread among poultry and wild aquatic birds in southern China and southeastern Asian countries including Vietnam. In Vietnam, a series of human cases of $\mathrm{H} 5 \mathrm{~N} 1$ virus infection have occurred sporadically in areas where serious $\mathrm{H} 5 \mathrm{~N} 1$ outbreaks among poultry have preceded and as of November 2010, 119 confirmed cases with 59 deaths have been reported since 2003 (WHO, 2010). Exposure to infected poultry was ascribed to the source of H5N1 infection in humans, and so far no human-to-human transmissions have been verified. In order to control the H5N1 outbreaks in poultry and the subsequent human sporadic infections, Vietnamese government has implemented the disease control program placing a nationwide mass-vaccination campaign as the principle policy of the program, besides with other activities including restrictions of animal movements, pre-emptive culling, a ban on waterfowl hatching. A nationwide large-scale vaccination was conducted in Oct-Nov 2005, Mar-Jun 2006, Aug-Nov 2006, and Mar-Jun 2007, where chickens and ducks were vaccinated with an inactivated H5N1 vaccine (Minh et al, 2009, Pfeiffer et al, 2007). Since then, the epidemic waves of H5N1 among poultry had apparently subsided and the cases have been absent for approximately 14 months until the end of May 2007 when the $4^{\text {th }}$ epidemic wave was identified in the Red River Delta (Minh et al., 2009). Lee et al. (2004) reported that long-term use of avian influenza vaccine among poultry in Mexico has aided the emergence of viruses with multiple sublineages separated from that of vaccine strain and subsequently allowed the newly emerged H5N2 strains spread to adjacent countries. Vietnam is a country where multiple clades of $\mathrm{H} 5 \mathrm{~N} 1$ virus have been endemic among poultry and it is, therefore, intriguing to monitor the distribution of avian influenza viruses in poultry raised in farms after introduction of the mass vaccination campaign, by which $\mathrm{H} 5 \mathrm{~N} 1$ strains were implicated to maintaine in reservoir(s) developing milder symptoms on H5N1 virus 
infections.

In the present study, throat and cloacal swab samples were obtained from apparently healthy poultry raised on farms in northern Vietnam during year 2006-2009 and were subjected for virus isolation and subsequent analyses to characterize pathogenicity of the isolated viruses and estimate their genetical backgrounds.

\section{Materials and Methods}

\section{1. Study sites and samples taken}

Three villages in Hanoi, three villages in Nam Dinh province, and two villages in Vinh Phuc province were chosen as the sites of sample collection (Fig. 1). The latest outbreaks, by the time of study period, occurred at the end of October 2005, the beginning of December 2005, and the end of December 2005, in Hanoi, Vinh Phuc and in Nam Dinh, respectively. Since a new wave of H5N1 epidemic among poultry have been reported more frequently in Nam Dinh province than in other areas in the early summer in 2007, we resumed collecting samples in September 2007 at Giao Thuy and Vu Ban districts where outbreaks were intensively reported, in Nam Dinh province.

Healthy poultry reared in farms located in Hanoi, Nam Dinh province, and Vinh Phuc province in northern Vietnam were collected in the period between October 2006 and December 2009 (Table 1). Throat and cloacal secretion were taken by swab from each poultry and suspended in $2 \mathrm{ml}$ of phosphate-buffered saline (PBS) supplemented with $0.5 \%$ bovine serum albumin, 10,000 units $/ \mathrm{ml}$ of penicillin, $10 \mathrm{mg} / \mathrm{ml}$ of streptomycin sulfate, and $0.3 \mathrm{mg} / \mathrm{ml}$ of gentamicin sulfate. All of the specimens were kept at $4^{\circ} \mathrm{C}$ during transportation to the laboratory for 4 to $6 \mathrm{hrs}$, and kept frozen at $-80^{\circ} \mathrm{C}$ until inoculation to embryonated eggs for virus isolation. 


\section{2. Virus isolation and hemagglutinin (HA) and neuraminidase (NA) subtyping}

A hundred (100) $\mu 1$ portion of each specimen was inoculated into the allantoic cavity of two 10-day-old embryonated hen's eggs and incubated at $35^{\circ} \mathrm{C}$ for 72 hrs unless death of the embryo was detected. After $72 \mathrm{hr}$-incubation or upon the embryo death, the allantoic fluids were tested for hemagglutinating activity as described elsewhere (Kida and Yanagawa, 1979). All of the allantoic fluids carrying hemagglutinating agents were tested further to determine subtypes for HA and NA by HA-inhibition (HI) (Salk, 1944) and NA-inhibition (NI) (Aymard-Henry et al., 1973) tests using specific antisera to A/PR/8/34 (H1N1), A/swine/Iowa/15/30 (H1N1), A/Singapore/1/57 (H2N2), A/duck/Ukraine/1/63 (H3N8), A/duck/Czech/56 (H4N6), A/whistling $\quad$ swan/Shimane/499/83 (H5N3),

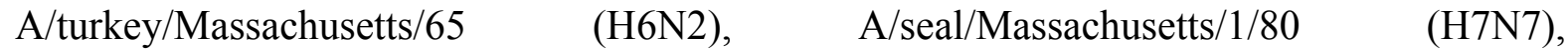

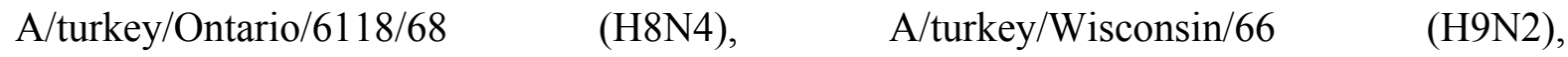
A/chicken/Germany/"N"/49 (H10N7), A/duck/England/56 (H11N6), and A/duck/Alberta/60/76 (H12N5), A/gull/Maryland/704/77 (H13N6), A/duck/Memphis/564/74 (H11N9) as described in previous studies (Kida and Yanagawa, 1979). Antisera specific to Newcastle disease virus strain Miyadera was also used to exclude hemagglutinating agents induced by Newcastle disease virus in the test.

\section{3. Nucleotide sequencing}

Nucleotide sequences of eight genes (PB2, PB1, PA, HA, NP, NA, M, and NS) of influenza A virus were determined as described elsewhere (Hoffmann et al., 2001). Briefly, viral RNA were extracted from all allantoic fluids carrying influenza A virus and reverse-transcribed. A series of PCR-amplified fragments corresponding to each gene were purified with QIAquick Gel Extraction Kit and sequenced on a CEQ 8000 DNA sequencer (Beckman Coulter, Inc.) using CEQ DTCS-Quick Start Kit. Nucleotide sequence alignment 
was performed on the GENETYX-MAC program (GENETYX CORPORATION) and the phylogenetic trees were generated using the neighbor-joining method with bootstrap analysis. Influenza A strains representing each of clade 1 to clade 2.5 for $\mathrm{H} 5$ gene, and strains representative of each of $\mathrm{PB} 2, \mathrm{~PB} 1, \mathrm{PA}, \mathrm{HA}, \mathrm{NP}, \mathrm{NA}, \mathrm{M}$, and NS genes deposited to GenBank were used for references and compared.

\section{4. Pathogenicity of influenza A H5N1 strains}

Pathogenicity of influenza A subtype H5N1 strains on poultry and on mammalian were tested as described elsewhere (Gao et al., 1999; WHO, 2004). Briefly, a $0.2 \mathrm{ml}$ portion of the 1:10 diluted allantoic fluid containing strain H5N1 was inoculated intravenously to eight 6-week-old chickens and intranasally to six 7-week-old ducks, and general condition were observed for 14 days. Six-week-old C57BL/6 mice were intranasally inoculated with a $0.05 \mathrm{ml}$ portion of the $1: 10$ serially diluted allantoic fluid containing an $\mathrm{H} 5 \mathrm{~N} 1$ strain $\left(10^{9.0} \mathrm{EID} 50 / \mathrm{ml}\right)$, and rates of death, weight loss and general condition were observed for 14 days post infection and mouse infectious dose 50 was determined. Allantoic fluid containing A/mountain hawk-eagle/Kumamoto/1/07 (10 ${ }^{8.83}$ EID50/ml, Shivakoti et al., 2010) was used as a control of virulent $\mathrm{H} 5 \mathrm{~N} 1$ strain to mice. All animals were maintained in the animal facilities of Tottori University and Hokkaido University and treated complying the Laboratory Animal Control Guidelines of each institute.

\section{Results}

\section{1. Isolation of avian influenza A viruses in northern Vietnam from 2006 to 2009}

In the period between 2006 and 2009, throat and cloacal secretion specimens were taken from 3,851 chickens, 2,922 ducks, and 240 Muscovy ducks for virus isolation (Table 
1). Five different subtypes of influenza A virus were isolated in the study, including $\mathrm{H} 3 \mathrm{~N} 8$, H6N2, H5N1, H11N9 and H12N5 from 16 (3 chickens and 13 ducks), 7 (Muscovy ducks), 1 (duck), 2 (ducks), and 1 (duck) poultry, respectively. Sequence analysis were performed on the eight genes of all 27 influenza A viruses isolated in the study, and seven representative strains were chosen considering differences in subtype and amino acid sequence homologies, as follows: Chicken/Vietnam/G14/08 (H3N8), Duck/Vietnam/G119/06 (H3N8), Duck/Vietnam/G12/08 (H5N1), Duck/Vietnam/G30/08 (H11N9), Duck/Vietnam/G32/08 (H11N9), Duck/Vietnam/G18/09 (H12N5), and Duck/Vietnam/G33/07 (H6N2) (Table 1).

\subsection{Characterization of the Duck/Vietnam/G12/08(H5N1) isolated from a duck}

Nucleotide sequencing and subsequent deduced amino acid analysis of the H5N1 strain Duck/Vietnam/G12/08 identified a highly cleavable sequence (PQRERRRKR/G) at the amino acids position 337 to 346 (GenBank accession number AB593447), which is found typically in the HA gene of HPAI strains. When Duck/Vietnam/G12/08 was inoculated intraveneously to chickens, all chickens were dead within 24 hrs post infection, indicating that the virus was a highly pathogenic to chickens-and IVPI (intravenous pathogenicity index) was estimated as 3.00 (OIE Manual, 2005). Contrary to the results observed in chickens, five of 6 ducks did not develop any significant symptoms by infection with the H5N1 strain. Relatively mild symptoms including transient lacrimation, appetite loss were observed in one duck caused by the virus challenge, and viruses had been shed for four days post infection.

Pathogenicity of the Duck/Vietnam/G12/08 (H5N1) was also tested on mice. Four out of 5 mice were dead within 11 days post infection with 1:10-diluted allantoic fluid, and more than $20 \%$ weight loss was observed even in the mouse survived. Two out of five mice 
were dead within 11 days post infection when 1:100-, 1:1,000- and 1:10,000-diluted allantoic fluid was inoculated. Significant weight loss was observed in all of the mice survived except one mouse challenged with 1:10,000-diluted allantoic fluid. When 1:100,000-diluted allantoic fluid was inoculated, four out of five mice survived, of those, weight loss was observed in two mice. Neither death nor significant weight loss was observed in all of the mice challenged with 1:1,000,000-diluted allantoic fluid. The dose lethal for $50 \%$ of mice $\left(\mathrm{MLD}_{50}\right)$ of this $\mathrm{H} 5 \mathrm{~N} 1$ strain was calculated as $10^{3.59} \mathrm{pfu}$ from this experiment. On the other hand, $\mathrm{MLD}_{50}$ of A/mountain hawk-eagle/Kumamoto/1/07 (H5N1) was $10^{1.52}$ pfu.

Phylogenetic analysis on HA gene revealed that Duck/Vietnam/G12/08 (H5N1) isolated in the study clustered into sublineage clade 2.3.4 that reported circulating predominantly among poultry in northern Vietnam from 2006 through 2007 (Fig. 2A). The seven other genes of Duck/Vietnam/G12/08 (H5N1) clustered also together with those of H5N1 strains sublineage clade 2.3.4 (Figs. 2B and 3). Sequence analysis of PB2 gene of Duck/Vietnam/G12/08 (H5N1) revealed that amino acid at position 627 was glutamic acid, indicating that Duck/Vietnam/G12/08 (H5N1) did not exhibit high virulence to mice. Amino acid substitutions at the positions 26, 27, 30, 31 and 34 in $\mathrm{M}$ gene were frequently observed in $\mathrm{H} 5 \mathrm{~N} 1$ strains resistant to amantadine. However, no amino acid substitutions were observed in $\mathrm{M}$ gene of Duck/Vietnam/G12/08 (H5N1), indicating that the strain was susceptible to amantadine. Sequence analysis also indicated that Duck/Vietnam/G12/08 (H5N1) was susceptible to oseltamivir, because amino acid substitution from histidine $(\mathrm{H})$ to tyrosine (T) at position 274 of NA, which was frequently observed in oseltamivir-resistant strains, was not found in the strain.

\section{3. Phylogenetic analysis of low pathogenic avian influenza viruses}

Phylogenetic analyses were performed for all seven representative strains 
[Chicken/Vietnam/G14/08 (H3N8), Duck/Vietnam/G119/06 (H3N8), Duck/Vietnam/G12/08

(H5N1), Duck/Vietnam/G30/08 (H11N9), Duck/Vietnam/G32/08 (H11N9), Duck/Vietnam/G18/09 (H12N5), and Duck/Vietnam/G33/07 (H6N2)] isolated from domestic poultry in northern Vietnam 2006-2009 in the study and compared with those strains deposited to GenBank (Figs. 2 and 3). Phylogenetic analyses were performed on all of the eight segments (PB2, PB1, PA, NP, M, NS, HA and NA) for each isolate. Six out of seven viruses except $\mathrm{H} 5 \mathrm{~N} 1$ were shown to contain eight gene segments closely related to viruses belonging to Asian or European wild-bird lineage. Although HA and NA genes of the two H11N9 isolates (Duck/Vietnam/G30/08 and Duck/Vietnam/G32/08) were almost identical, showing more than $99 \%$ homologies to each other, four (PB2, PA, NP, and NS) out of six internal genes of the two H11N9 strains were shown to be categorized into different lineages (Fig. 3). The H3N8 viruses isolated from chickens in the study, represented by Chicken/Vietnam/G14/08, were unique in composition of genes encoding surface proteins as well as internal proteins. For example, the internal genes of PB2, PB1, PA and NS carried by the virus were closely related to those of the H6N2 virus isolated from a duck (Duck/Vietnam/G33/07) in the study, rather than other H3 strains reported previously, showing more than $98 \%$ homologies to each other. As of more interest, HA gene of Chicken/Vietnam/G14/08 (H3N8) was shown aberrant, because even the closest counterpart of the HA gene in amino acid sequence was those of $\mathrm{H} 3$ strains isolated from wild birds in Alaska in 2007 and Hong Kong in 2009, showing only 93\% homologies to each other.

\section{Discussion}

A HPAI virus subtype H5N1 was isolated from an apparently healthy duck reared in a farm in Nam Dinh province in 2008. In our previous study conducted in October and November 2006 during the absence of prominent H5N1 outbreaks among poultry (Takakuwa 
et al., 2010), we reported that at least five out of 1,106 sera of ducks contained sole H5N1 specific HI and NI antibodies together with the presence of anti-NP/M specific and anti-NS1 specific antibodies, indicating that these five ducks had been infected with H5N1 viruses, comparatively recently at the time of sample collection. Of those, four ducks were collected in Nam Dinh province where Duck/Vietnam/G12/08 (H5N1) was isolated in this study. It was hypothesized that $\mathrm{H} 5 \mathrm{~N} 1$ viruses once maintained among duck population have abruptly transmitted to other poultry including chicken, Muscovy duck, and quail and may have caused the outbreak occurred in Nam Dinh province in early summer of 2007 (Takakuwa et al, 2010). The hypothesis is supported by a report addressing that ducks became the most affected species in the latest H5N1 outbreak in northern Vietnam after the progressively increasing percentage over 4 years (Minh et al., 2009). Isolation of H5N1 virus from an apparently healthy duck in this study is an evidence to support the hypothesis. These findings indicate that domestic ducks play a pivotal role in maintaining and transmitting virus to cause outbreaks in northern Vietnam.

MLD $_{50}$ of Duck/Vietnam/G12/08 (H5N1) was approximately 100-fold higher than that of $\mathrm{A} /$ mountain hawk-eagle/Kumamoto/1/07, indicating that the strain isolated in the study was not highly pathogenic on mice compared with A/mountain hawk-eagle/Kumamoto/1/07. Previous reports addressed that lysine (K) at position 627 of PB2 was one of the major determinants of influenza virus replicative potential in mice (Hatta et al., 2001; Shinya et al., 2004). Strain A/mountain hawk-eagle/Kumamoto/1/07 used as a control of virulent H5N1 subtype in the animal experiment contains lysine $(\mathrm{K})$ at position 627 of PB2. Contrary to A/mountain hawk-eagle/Kumamoto/1/07, Duck/Vietnam/G12/08 (H5N1) contains glutamic acid (E) at the same position. The data may explain a relatively low pathogenicity of Duck/Vietnam/G12/08 (H5N1) strain on mice compared with that of $\mathrm{A} /$ mountain hawk-eagle/Kumamoto/1/07. 
It is well known that a single amino acid substitutions at any of positions $26,27,30$, 31 and 34 of the M2 protein can confer resistance against amantadine (Hay et al., 1985; Abed et al., 2005) and substitution from histidine (H) to tyrosine (T) at amino acid position 274 in NA gene confers a high-level of resistance to oseltamivir (Gubareva et al, 2001; Le et al, 2005). H5N1 strains possessing these mutations or the substitution are reported among H5N1 strains circulating in humans, however, no amino acid substitutions were found in either of M2 or NA gene of Duck/Vietnam/G12/08 (H5N1) isolated in the study. As far as M2 and NA genes concerned, it may be indicated that Duck/Vietnam/G12/08 (H5N1)-like strains have been circulating among ducks exclusively in the area keeping away from chances of gene exchange with other H5N1 strains of different areas origin.

Previous reports indicated that the distribution of $\mathrm{H} 5 \mathrm{~N} 1$ strains were different in sublineages in northern and southern Vietnam (Nguyen et al, 2008; Wan et al, 2008). Strains belonging to clade 2.3.4 sublineage were predominantly isolated in northern Vietnam in 2007; however, clade 1 was predominant in southern Vietnam in the same year. Phylogenetic analysis on HA gene revealed that H5N1 strains belonging to clade 2.3.4 has still been circulating among poultry in northern Vietnam since year 2007. Of note, each of the seven other genes carried by the H5N1 strain isolated in the study, also converged into a cluster to which each of the corresponding genes of H5N1 strains isolated in 2007 belonged, indicating that no remarkable reassortments have occurred in H5N1 strains since 2007 in the area (Fig. 2A,B, 3).

HPAI subtype H5N1 viruses were first detected in 1996 in geese in Guangdong, China (Xu et al., 1999) and then spread to ducks in southern China without killing them (Chen et al., 2004). Chen et al. (2004) demonstrated that almost all HPAI H5N1 viruses that were isolated from apparently healthy ducks in China from 1999 through 2002 caused lethal and systemic infection in chickens. In late 2002, viruses emerged in Hong Kong, then spread 
to Vietnam and Thailand ( $\mathrm{Li}$ et al., 2004), were found to kill ducks (Sturm-Ramirez et al., 2004). Although a series of H5N1 isolates with sublineage clade 2.3 .4 from ducks in northern Vietnam in 2007 (Fig. 2A) still killed ducks, Duck/Vietnam/G12/08 was isolated from apparently healthy duck in northern Vietnam in 2008 and did not kill ducks in an experimental infection. This finding supports several reports describing the pathogenicities of recent $\mathrm{H} 5 \mathrm{~N} 1$ virus isolates in Asian countries varied from completely nonpathogenic to highly lethal to ducks (Sturm-Ramirez et al., 2005; Hulse-Post DJ et al., 2007; Middleton et al., 2007; Vascellari et al., 2007).

Phylogenetic analyses revealed that there are interesting evidences of multiple lineages and reassortments among the viruses isolated in northern Vietnam. Two representative H11N9 strains (Duck/Vietnam/G30/08 and Duck/Vietnam/G32/08) were isolated in farms located at close proximity, and their HA and NA genes were homologous to each other with more than $99 \%$ similarity. However, each of PB2, PA, NP, and NS genes were found to be categorized into separate groups, indicating that reassortments have occurred at comparatively higher rate among these low pathogenic avian influenza A subtypes. Chicken/Vietnam/G14/08 (H3N8) isolated from a chicken in 2008 in the study was found unique in compositions of genes encoding surface as well as internal proteins. The PB2, PB1, PA and NS genes of the strain were most closely related to those of the H6N2 virus isolated from a duck in 2007 (Duck/Vietnam/G33/07), showing more than 98\% homologies to each other. Furthermore, Chicken/Vietnam/G14/08 (H3N8) possess HA gene unique in sequence alignment, which is closest to those of $\mathrm{H} 3$ strains isolated from wild birds in Alaska in 2007 and Hong Kong in 2009, showing merely 93\% homologies. The Chicken/Vietnam/G14/08 (H3N8) strain was isolated from a healthy chicken and, it is estimated that aberrant HA trait of the strain was induced probably in a process of adaptation of the strain to chicken. It is important, therefore, to monitor the prevalence of influenza 
viruses among healthy poultry from the viewpoints of emergence of new viruses by the mechanism of reassortments and mutations in the area where $\mathrm{H} 5 \mathrm{~N} 1$ influenza viruses with multiple subtypes were endemic.

\section{Conflict of interest statement}

None of the authors of this paper has a financial or personal relationship with other people or organizations that could inappropriately influence or bias the content of the paper.

\section{Acknowledgements}

This article has been supported by the Program of Founding Research Centers for Emerging and Reemerging Infectious Diseases, the Ministry of Education, Culture, Sports and Technology, Japan. 


\section{References}

Abed, Y., Goyette, N., Boivin, G., 2005. Generation and characterization of recombinant influenza A (H1N1) viruses harboring amantadine resistance mutations. Antimicrob. Agents Chemother., 49, 556-559.

Aymard-Henry, M., Coleman, M.T., Dowle, W.R., Laver, W.G., Schild, G.C., Webster, R.G., 1973. Influenza virus neuraminidase and neuraminidase-inhibition test procedures. Bulletin of World Health Organization 48, 199-202.

Chen, H., Deng, G., Li, Z., Tian, G., Li, Y., Jiao, P., Zhang, L., Liu, Z., Webster, R.G., Yu, K., 2004. The evolution of H5N1 influenza viruses in ducks in southern China. Proc. Natl Acad.Sci.U. S. A., 101, 10452-10457.

Gao, P., Watanabe, S, Ito, T., Goto, H., Wells, K., McGregor, M., Cooley, A. J., Kawaoka, Y., 1999. Biological heterogeneity, including systemic replication in mice, of H5N1 influenza A virus isolates from humans in Hong Kong. J. Virol., 73, 3184-3189.

Gubareva, L.V., Kaiser, L., Matrosovich, M.N., Soo-Hoo, Y., Hayden, F. G., 2001. Selection of influenza virus mutants in experimentally infected volunteers treated with oseltamivir. J. Infect. Dis., 183, 523-531.

Hatta, M., Gao, P., Halfmann, P., Kawaoka, Y., 2001. Molecular basis for high virulence of Hong Kong H5N1 influenza A viruses. Science 293, 1840-1842.

Hay, A. J., Wolstenholme, A. J., Skehel, J. J., Smith, M. H., 1985. The molecular basis of the specific anti-influenza action of amantadine. EMBO J. 4, 3021-3024.

Hoffmann, E., Stech, J., Guan, Y., Webster, R.G., Perez, D.R., 2001. Universal primer set for the full-length amplification of all influenza A viruses. Arch. Virol., 146, 2275-2289.

Hulse-Post, D.J., Franks, J., Boyd, K., Salomon, R., Hoffmann, E., Yen, H.L., Webby, R.J., Walker, D., Nguyen, T.D., Webster, R.G., 2007. Molecular changes in the polymerase genes (PA and PB1) associated with high pathogenicity of $\mathrm{H} 5 \mathrm{~N} 1$ influenza virus in mallard ducks. J.Virol., 81, 8515-8524.

Kida, H., Yanagawa, R., 1979. Isolation and characterization of influenza a viruses from wild free-flying ducks in Hokkaido. Jpn. Zentralbl. Bakteriol. A., 244, 135-143. 
Le, Q.M., Kiso, M., Someya, K., Sakai, Y.T., Nguyen, T.H., Nguyen, K.H., Pham, N.D.,

Ngyen, H.H., Yamada, S., Muramoto, Y., Horimoto, T., Takada, A., Goto, H,, Suzuki,

T., Suzuki, Y,, Kawaoka, Y.. 2005. Avian flu: isolation of drug-resistant H5N1 virus.

Nature 437, 1108.

Lee, C.W., Senne, D.A., Suarez, D.L., 2004. Effect of vaccine use in the evolution of Mexican lineage H5N2 avian influenza virus. J.Virol., 78, 8372-8381.

Li, K.S., Guan, Y., Wang, J., Smith, G.J., Xu, K.M., Duan, L., Rahardjo, A.P., Puthavathana, P., Buranathai, C., Nguyen, T.D., Estoepangestie, A.T., Chaisingh, A., Auewarakul, P., Long, H.T., Hanh, N.T., Webby, R.J., Poon, L.L., Chen, H., Shortridge, K.F., Yuen, K.Y., Webster, R.G., Peiris, J.S., 2004. Genesis of a highly pathogenic and potentially pandemic H5N1 influenza virus in eastern Asia. Nature 430, 209-213.

Middleton, D., Bingham, J., Selleck, P., Lowther, S., Gleeson, L., Lehrbach, P., Robinson, S., Rodenberg, J., Kumar, M., Andrew, M., 2007. Efficacy of inactivated vaccines against H5N1 avian influenza infection in ducks. Virology, 359, 66-71.

Minh, P.Q., Morris, R.S., Schauer, B., Stevenson, M., Benschop, J., Nam, H.V., Jackson, R., 2009. Spatio-temporal epidemiology of highly pathogenic avian influenza outbreaks in the two deltas of Vietnam during 2003-2007. Prev.Vet. Med., 89, 16-24.

Nguyen, D.C., Uyeki, T.M., Jadhao, S., Maines, T., Shaw, M., Matsuoka, Y., Smith, C., Rowe, T., Lu, X., Hall, H., Xu, X., Balish, A., Klimov, A., Tumpey, T.M., Swayne, D.E., Huynh, L.P., Nghiem, H.K., Nguyen, H.H., Hoang, L.T., Cox, N.J., Katz, J.M., 2005. Isolation and characterization of avian influenza viruses, including highly pathogenic H5N1, from poultry in live bird markets in Hanoi, Vietnam, in 2001. J.Virol., 79, 4201-4212.

Nguyen T.D., Nguyen V., Vijaykrishna D., Webster R.G., Guan Y., Peiris J.S.M., Smith G.J.D. 2008. Multiple sublineages of influenza a virus (H5N1), Vietnam, 2005-2007. Emerg. Infect.Dis., 14, 632-636.

Office International des Epizooties,, 2005. Manual of diagnostic tests and vaccines for terrestrial animals. Part 2, Section 2.1, Chapter 2.1.14. World Organization for Animal 
Health, Paris, France, ISBN: 929044622.

Pfeiffer D.U., Minh P.Q., Martin V., Epprecht M., Otte M.J., 2007. An analysis of the spatial and temporal patterns of highly pathogenic avian influenza occurrence in Vietnam using national surveillance data. Vet. J., 174, 302-9.

Salk, J.E., 1944. A simplified procedure for titrating hemagglutinating capacity of influenzavirus and the corresponding antibody. J.Immunol., 49, 87-98.

Shivakoti, S.,Ito, H., Otsuki, K., Ito, T., 2010. Characterization of H5N1 Highly Pathogenic Avian Influenza Virus Isolated from a Mountain Hawk Eagle in Japan. J. Vet. Med. Sci., 72, 459-463.

Sturm-Ramirez, K.M., Hulse-Post, D.J., Govorkova, E.A., Humberd, J., Seiler, P., Puthavathana, P., Buranathai, C., Nguyen, T.D., Chaisingh, A., Long, H.T., Naipospos, T.S., Chen, H., Ellis, T.M., Guan, Y., Peiris, J.S., Webster, R.G., 2005. Are ducks contributing to the endemicity of highly pathogenic H5N1 influenza virus in Asia? J.Virol., 79, 11269-11279.

Sturm-Ramirez, K.M., Ellis, T., Bousfield, B., Bissett, L., Dyrting, K., Rehg, J.E., Poon, L., Guan, Y., Peiris, M., Webster, R.G., 2004. Reemerging H5N1 influenza viruses in Hong Kong in 2002 are highly pathogenic to ducks. J.Virol., 78, 4892-4901.

Shinya, K., Hamm, S., Hatta, M., Ito, H., Ito, T., Kawaoka, Y., 2004. PB2 amino acid at position 627 affects replicative efficiency, but not cell tropism, of Hong Kong H5N1 influenza A viruses in mice. Virology 320, 258-266.

Takakuwa, H., Yamashiro, T., Le, M.Q., Phuong, L.S., Ozaki, H., Tsunekuni, R., Usui, T., Ito, H., Yamaguchi, T., Ito, T., Murase, T., Ono, E., Otsuki, K., 2010. Possible circulation of $\mathrm{H} 5 \mathrm{~N} 1$ avian influenza viruses in healthy ducks on farms in northern Vietnam. Microbiol. Immunol., 54, 58-62.

Vascellari, M., Granato, A., Trevisan, L., Basilicata, L., Toffan, A., Milani, A., Mutinelli, F., 2007. Pathologic findings of highly pathogenic avian influenza virus A/Duck/Vietnam/12/05 (H5N1) in experimentally infected pekin ducks, based on immunohistochemistry and in situ hybridization. Vet. Pathol., 44, 635-642. 
Wan, X.F., Nguyen, T., Davis, C.T., Smith, C.B., Zhao, Z.M., Carrel, M., Inui, K., Do, H.T., Mai, D.T., Jadhao, S., Balish, A., Shu, B., Luo, F., Emch, M., Matsuoka, Y., Lindstrom, S.E., Cox, N.J., Nguyen, C.V., Klimov, A., Donis, R.O., 2008. Evolution of highly pathogenic H5N1 avian influenza viruses in Vietnam between 2001 and 2007. PLoS ONE 3, e3462.

World Health Organization Global Influenza Programme., 2004. WHO manual on animal influenza diagnosis and surveillance, p. 62-63.

World Health Organization., 2010. Confirmed Human Cases of Avian Influenza A (H5N1). http://www.who.int/csr/disease/avian_influenza/country/en/

Xu, X., Subbarao, K., Cox, N.J., Guo, Y., 1999. Genetic characterization of the pathogenic influenza A/Goose/Guangdong/1/96 (H5N1) virus: similarity of its hemagglutinin gene to those of H5N1 viruses from the 1997 outbreaks in Hong Kong. Virology 261, 15-19. 


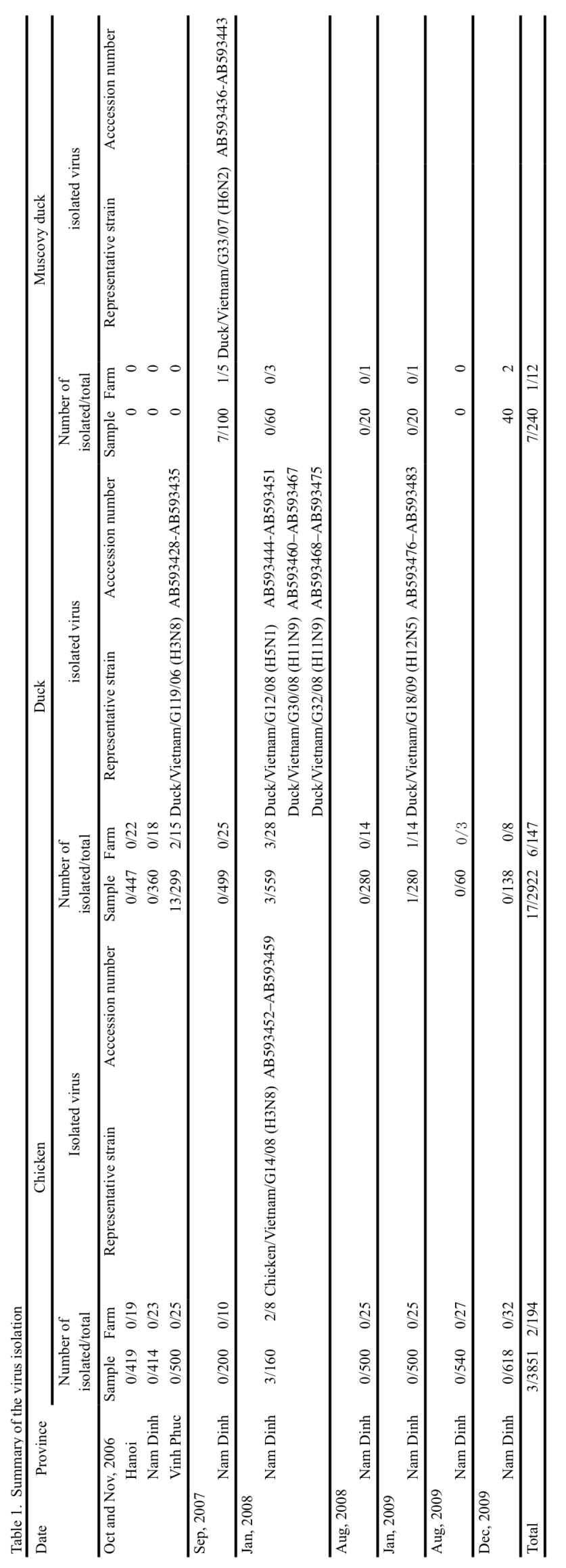




\section{Figure legends}

Fig 1. Location of the sampling sites in northern Vietnam from 2006 to 2009. Symbols show name of the districts and date in Hanoi, Vinh Phuc and Nam Dihn provinces where the samplings were performed.

Fig. 2. Phylogenetic relationship of HA and NA genes of the viruses isolated in northern Vietnam. Phylogenetic trees include all the seven representative strains isolated from domestic poultry in northern Vietnam 2006-2009 and selected reference isolates. Trees are shown for HA and NA genes of each isolate as follows: A) H5, B) N1, C) H3, D) N8, E) H6, F) N2, G) H11, H) N9, I) H12 and J) N5. The viruses isolated during this study are shown in red text. The coding sequences of the full genomes of all viruses were sequenced and analyzed phylogenetically. Numbers to the right of the figure refer to World Health Organization influenza (H5N1) clade designations. Virus names described in this study are shown in red text. Scale bar, 0.01 substitutions per site.

Fig. 3. Phylogenetic relationship of the internal gene segments of the viruses isolated in northern Vietnam. Phylogenetic trees include all the seven representative strains isolated from domestic poultry in northern Vietnam 2006-2009 and selected reference isolates. Trees are shown for all 6 internal segments of each isolate as follows: A) PB2, B) PB1, C) PA, D) NP, E) M and F) NS. The viruses isolated during this study are shown in red text. The coding sequences of the full genomes of all viruses were sequenced and analyzed phylogenetically. Scale bar, 0.01 substitutions per site. 
Fig 1.

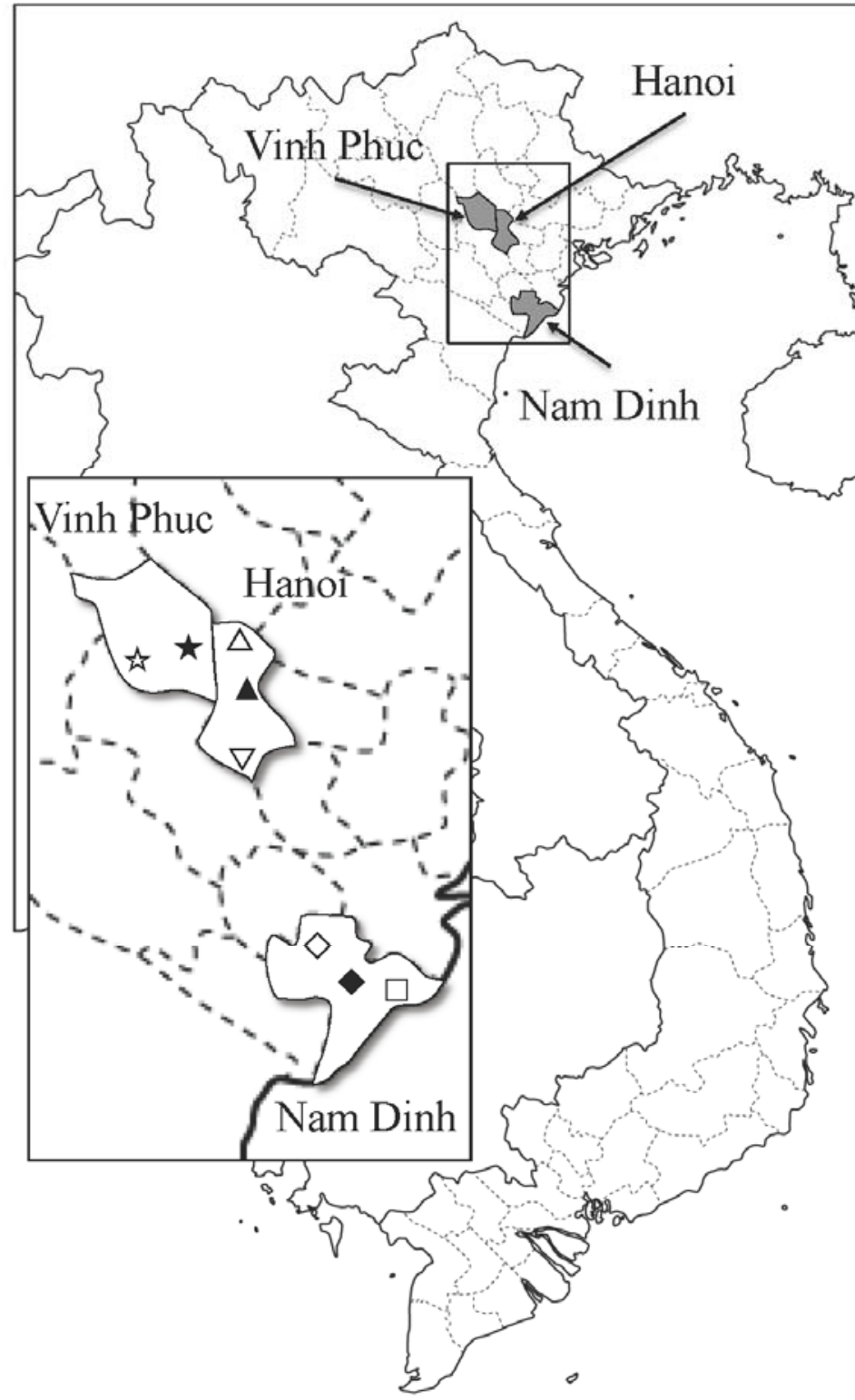

Vinh Phuc

$\star$ : Binh Xuyen (Nov. 2006)

ฟ: Vinh Tuong (Nov. 2006)

Hanoi

$\triangle$ : Soc Son (Oct. 2006)

$\boldsymbol{\Delta}$ : Dong Anh (Oct. 2006)

$\nabla:$ Thanh Tri (Oct. 2006)

Nam Dinh

$\diamond:$ Vu Ban (Nov. 2006, Sep. 2007)

Truc Ninh (Nov. 2006)

$\square$ : Giao Thuy (Nov. 2006,

Sep. 2007, Jan. and Aug. 2008, Jan., Aug. and Dec. 2009) 
Fig 2.

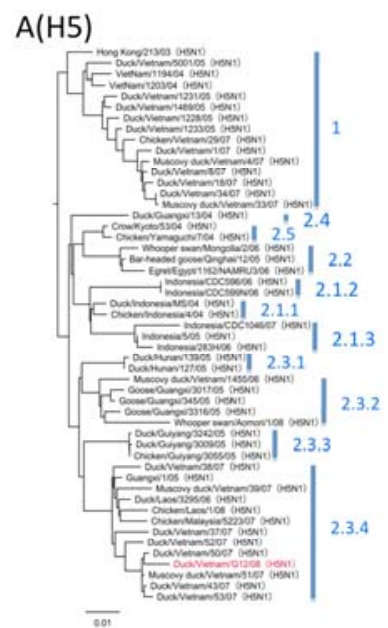

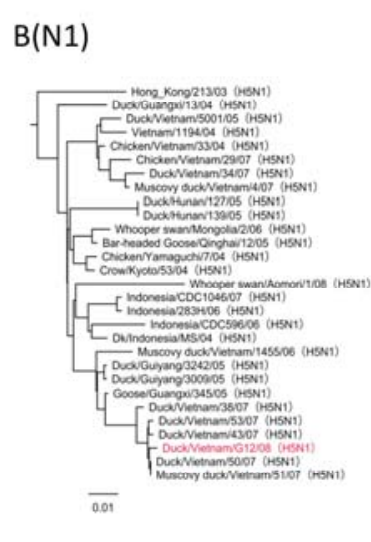

$E(H 6)$

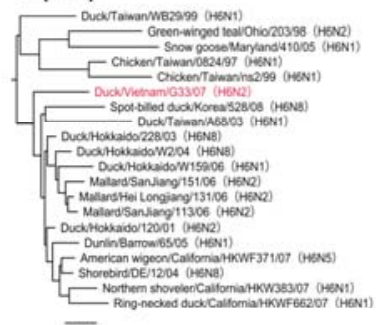

0.01

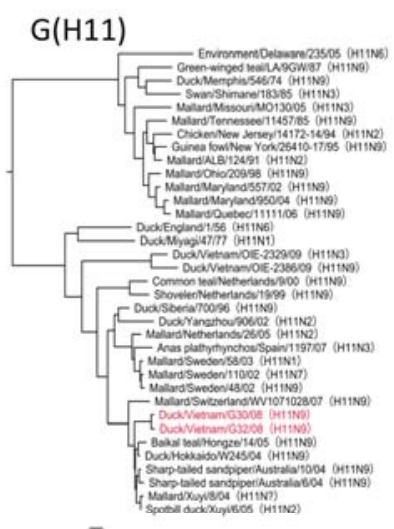

0.0

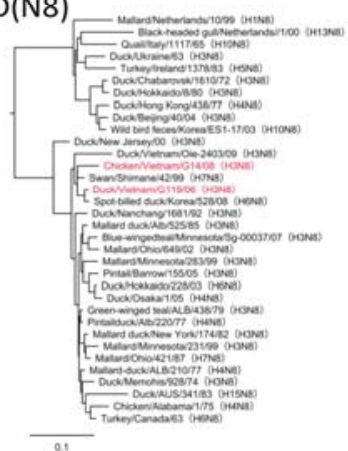

F(N2)

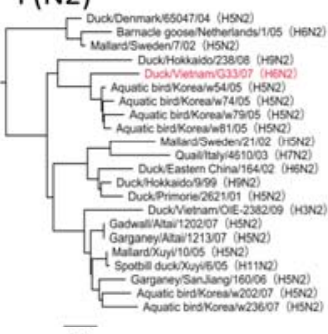

0.01

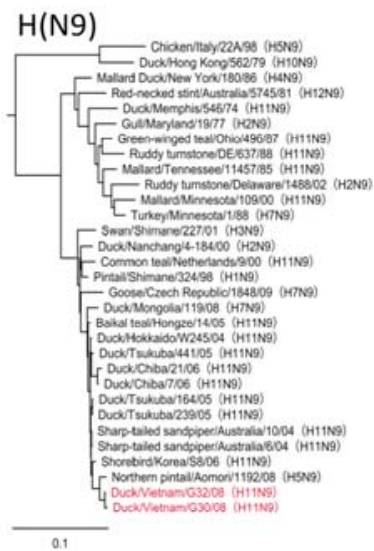

J(N5)

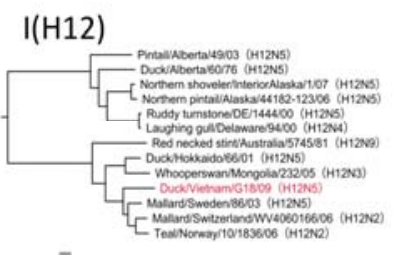

$-$

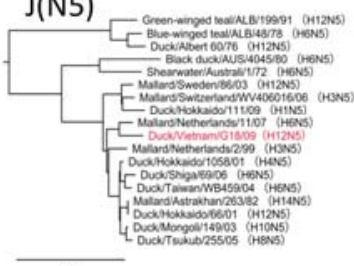


Fig 3.
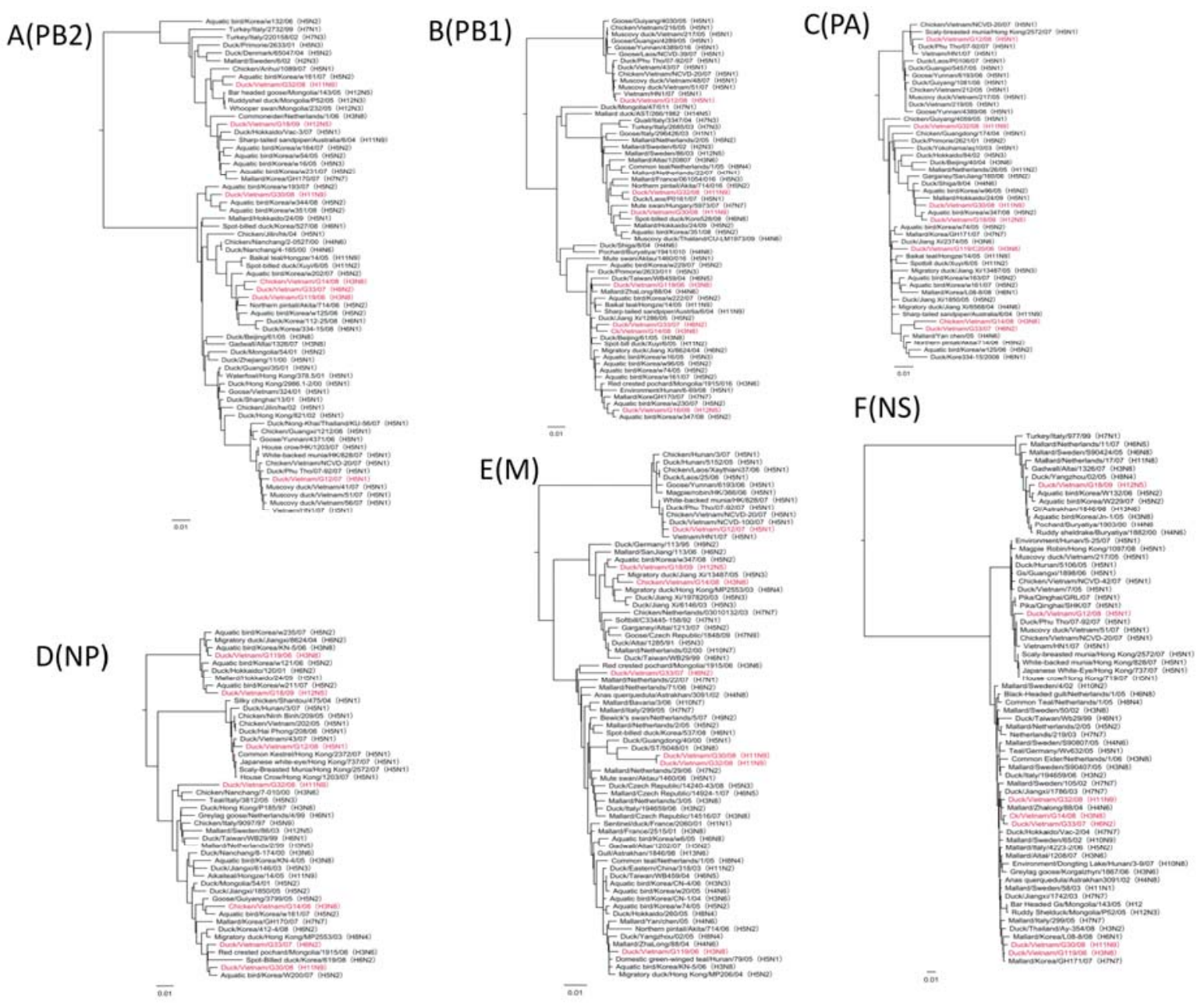